\title{
ILLIBERAL PEACE: PROMISES AND PROBLEMS
}

DOI: $10.20542 / 2307-1494-2021-1-207-210$

Owen C., Juraev Sh., Lewis D., Megoran M., Heathershaw J. Interrogating Illiberal Peace in Eurasia: Critical Perspectives on Peace and Conflict. - London; Lanham, Maryland: Rowman \& Littlefield, 2018. 305 p.

"Interrogating Illiberal Peace in Eurasia" is a collection of works exploring conflicts in Central Eurasia (including the South Caucasus, parts of the Middle East, and Xinjiang) through analyzing authoritarian perspectives on conflict management. Questioning typical approaches to peace that revolve around neoliberal ideas such as democratization, free global markets, and development, the authors offer new understanding of conflict management in several countries of Central Eurasia. Attempts to apply Western liberal democratization to the post-Soviet space and its subsequent decline have stimulated the emergence of illiberal local and regional tactics for dealing with conflict and peacekeeping. These kinds of tactics are hardly in line with standard liberal conflict resolution and peacebuilding methods and are categorized by the volume's authors as Authoritarian Conflict Management (ACM). They define Authoritarian Conflict Management as "the prevention, de-escalation or termination of organized rebellion or other mass social violence through methods that rely on instruments of state coercion and hierarchical structures of power to re-establish political order and stability and eschew liberal practices of negotiated settlement, third-party mediation and constraints on the use of force" (p. 12). This definition provides a broad framework for exploring multiple tactics of conflict resolution. The book explores how such "coercion and hierarchical structures" are created, utilized, and legitimized by both nation-state and local actors.

Since the Central Eurasian cultures have their own patronage-client means of creating harmony, it seems natural that these historically much older regional methods would take the lead in conflict resolution. However, as shown by different chapters in this volume, the use of such methods has often led to ambiguous outcomes; where positive outcomes could be traced, lasting peace is still not likely as underlying causes are managed rather than resolved. These methods appear to promote control of space, economy, and discourse, in contrast to liberal models that focus on encouraging and inserting ideas of tolerance into the population, as suggested by Khamidov, Megoran, and Heathershaw (p. 243). Based on the various findings made on the basis of individual case studies in this volume, the analysis of multiple ways of understanding and dealing with conflicts in Central Eurasia does provide insight into potential outcomes of conflicts in the region. Adding to the existing literature about post-Soviet nationalism and ethnic conflict, this book provides valuable lessons and recommendations for current peacebuilding in Central Eurasia.

The editors build up on the idea already well-established in the current literature on the region. They agree that Western sensibilities were exported to the East during the colonization era and upset or undermined traditional interethnic relations in parts of Eurasia (as well as other regions) through identity politics. Through this lens the editors bring together a well-balanced exploration of conflict management (pp. 3-4). Rather than focusing on military or repressive tactics alone, most chapters focus on unique forms of peacebuilding and both the subversion and maintenance of traditional power structures. In a chapter on Azerbaijan, they explore female liberation and creation of cross cultural empathy through writing (Mandaville's chapter, pp.73-92). There are examples of patronage 
systems that both keep citizens safe and perpetuate conflict. The book also explores and tries to explain both the influence and lack of influence of historical and modern conditions on conflict management patterns across the region, questioning how scholars use that context.

Manipulation of narrative in a Western-influenced nationalistic and ethnocentric way can extend modern narratives of conflict into the past, making them appear more long-term even when they are not necessarily connected to distant historical events. Sahadeo examines conflict between Uzbek and Kyrgyz people in the Fergana Valley and argues that the continuation of stereotypes and ethnic divisions makes ethnic insecurity more pronounced in times of crisis (p. 43). State control of the current narrative of the nation has led to Kyrgyz-centric political and social atmosphere in Kyrgyzstan. Sahadeo emphasizes the need to reexamine the past and Islam as means to find common ground for the people of the Kyrgyz Republic to create a cohesive civic identity and limit ethnic conflict (pp. 41, 4546). Promotion of a narrative of tolerance has not succeeded, but utilization of historic interethnic social structures has been shown to be successful in the town of Aravan, Osh region of Kyrgystan (see chapter by Khamidov, Megoran, and Heathershaw, pp. 195-219) and in the Jabbar Rasulov district of Tajikistan's Sughd region (see chapter by Hojiev and Kreikemeyer, pp. 121-144).

Likewise, Yin's exploration of the history of Chinese influence in Xinjiang finds a similar change of narrative linked to current conflicts. The shift towards Western interpretation of justice and conflict, coupled with pressures from Central Asia and colonial influence in China, led to the changing of official rhetoric in the 1970s to focus on ethnic identity and not class politics (pp. 188-189). This focus on ethnic identity coincides with the rise in the use of repressive tactics focused on the Uighur Muslims' identity by the Chinese State and Islamic terrorism in China. Both chapters on the Uighur problem conclude that current acts of ethnic repression and discrimination have only served to intensify these conflicts and have not created peace. Jones' chapter shows that attempted assimilation of Uighur through destruction of language (p. 67) or the more extreme tactics of the Chinese state involving harassment, re-education, and criminalization of religion (pp. 55-68) have proved to be ineffective methods for ending or even managing the conflict.

The effect of national language policies on minority ethnicities is explored in Khan's chapter. He points at a nonviolent but still discrimination-based exodus of minority groups from post-Soviet Central Eurasian countries as their governments instated the titular minority language as the national language (replacing Russian), making it harder for other longtime resident groups to gain societal and economic success or even survive (pp. 145168). These kinds of laws created conflicts and spurred cross-border movements of people.

Hojiev and Kreikemeyer show how traditional ways of interacting based on the patronage-client relationships of the past have made relations between the Tajiks and the Uzbeks in the Jabbar Rasulov district, mainly rural province of Tajikistan, relatively peaceful and created an attitude of acceptance among both ethnic groups (p. 121). Because of existing respect among groups, the Uzbeks in the region have been less concerned about language policy changes and have instead developed a perception that, for their children to live well and peacefully in Tajikistan, it is simply necessary to learn Tajik as well (chapter by Hojiev and Kreikemeyer, p. 133).

However, Lottholtz's take at the same issues shows how simply ending outbreaks of physical violence without ensuring post-conflict justice may impede long-term conflict resolution and make future conflict more likely (p. 115). While, in their respective chapters, Lottholtz, Zhirukhina, and Sharan/Bose show how patronal systems lead to further conflict, 
Hokiev/Kreikemeyer, Kutmanaliev, Khamidov, Megoran, and Heathershaw demonstrate how these traditional power structures help create and keep peace.

Patrimonial systems of power were used even during the 2010 Osh Massacre and related conflicts to protect citizens and quell violence. What is interesting in these accounts is that some of the most successful reductions of violence were accomplished both within and outside of traditional norms. Kutmanaliev outlines how a local female leader named Datka was chosen in the Kalinin neighborhood of the city of Osh to organize security measures, in a pattern that hardly conforms to patriarchal modes of operation. She was able to keep the majority of her neighborhood safe by using her personal ties to the community and the space around her strategically within the patronal system (Kutmanaliev's chapter, pp. 214-215). Similarly Khamidov, Megoran, and Heathershaw's narrative about the same events in Aravan demonstrates the involvement of women who found a way around traditional patriarchs, but still used social relationships and collaboration to successfully calm violence (p. 237). These two examinations of the nontrivial and less known sides of the ethnic violence in Kyrgyzstan in 2010 show that those acting within these kinds of patronal/cultural systems had more success in utilizing them to create stability.

Sharn and Bose evaluate the use of existing patronal systems in Afghanistan as a means of distributing foreign funds meant to stabilize the economy and the nation (pp. 249266). Their findings show how these attempts have actually led to corruption, theft, and misuse of funds, thus, ironically, feeding into the Taliban's propaganda (p. 263). The U.S.' lack of knowledge of patronal systems and reliance on a "strong man" in the capital to shift the power dynamics towards a Western-style democratic/market system led to a failure of stabilization efforts in Afghanistan (pp. 251-253). Conversely, the Russian Federation managed to achieve relative success in stabilizing Chechnya after years of internal conflict by a combination of means, including reliance on local strongmen, the Kadyrov family, clan, and their forces to manage security and backing him with large subsidies to the region (Zhirukhina's chapter, p. 283). While patronage-client power structures are clearly essential to the future of conflict resolution and peace building in Central Eurasia, their utilization is too complex to single out any particular tactics across the board.

Patrimonial systems of power are a cultural trait that had existed throughout the history of the broader region and understanding how they are structured uniquely in each country and area is crucial to the future of conflict resolution and peacebuilding in Central Eurasia. This multi-cultural and complex region requires knowledge of both long-term history of its peoples and modern history and political climate that may have more influence on current events there (Yin's chapter, pp. 188-189; Sahadeo's chapter, pp. 48-49). It is up to the people of each culture to choose for themselves which aspects of their beliefs and practices continue throughout time.

Overall, the volume provides a lot of data and historical influences to consider as scholars attempt to understand Central Eurasian conflicts. Instances of ACM solutions appear to have both positive and negative outcomes for conflicts across the region. The book shows that each situation needs to be addressed in its own merit, by taking into consideration local cultural power structures, economic norms, history of the region, and current political climate. The Western-centered ideas of identity and peace-building cannot be applied uniformly, if at all, especially in regions that have a unique history of space sharing between many cultures. These ideas, however, were already introduced to the area and their effect on interethnic relations should be accounted for. New conceptions of identity and nationalism mean that it is hardly enough for the peoples of the region to be simply reminded of historic ways of interacting and understanding one another. Instead, it is necessary to develop innovative means of generating peace and empathy. The complexity 
of the contributing factors and outcomes makes it hard to draw a clear conclusion from these collected works, but provides a good starting point for examining modern peacebuilding in Central Eurasia.

For readers who seek to understand conflict and resolution in Central Eurasia, it is highly recommended to read all the chapters included in "Interrogating Illiberal Peace in Eurasia" before they draw any conclusions. The volume as a whole gives a comprehensive view of the contributing factors to both violence and peacebuilding, including contextual environment, outside influences, history, political climate, cultural systems, and economic issues. However, the nuanced approach to these factors taken by the books' authors prevents them from prescribing clear solutions - instead, it indicates areas to which special attention should be paid, in order to prevent or more effectively end both ethnic and nationalist conflicts in the region. The book provides an overview of atypical peacekeeping tactics that can be placed in the category of Authoritarian Conflict Management, with no bias towards their success or failure.

This book strongly demonstrates how Western ideals of liberal peace and the tactics associated with them are not the only solutions that may work out to reduce or end violence and how certain ACM tactics may in fact be more effective and viable in the region of Central Eurasia. When examining instances of nationalist or interethnic conflict, it is important to keep in mind that there are no universal laws regulating identity or nationalism that are essentially ideological conceptions. Ethnicity does not determine political views or personal responses to calls to action regarding nationalism. ${ }^{1}$ For those studying Central Eurasia this is especially true: how we conceptualize identity, conflict, and peace will be a major factor in the future success of conflict resolution and peacebuilding in the region. The myriad methods used in similar conflicts and especially the multiple strategies used during the 2010 Kyrgyz-Uzbek clashes in Kyrgyzstan and explored in this book show how critical tailoring tactics to local factors is for Central Eurasia.

Angeline Nesbit (USA)

European University in Saint Petersburg; Puget Sound Emerging Museum Professionals ORCID: 0000-0003-2653-7044

(C) A.Nesbit, 2021

\section{ENDNOTES}

\footnotetext{
${ }^{1}$ Giuliano E. Constructing Grievance: Ethnic Nationalism in Russia's Republics. - Ithaca (N.Y.); London: Cornell University Press, 2011. P. 214.
} 